Research Article

\title{
Behavior of an Innovative Square Composite Column Made of Four Steel Tubes at the Corners and Corrugated Steel Batten Plates on all Sides
}

\author{
Chengquan Wang $\left(\mathbb{D},{ }^{1}\right.$ Zou Yun $\mathbb{1}^{1},{ }^{1}$ Jinxin Kang, ${ }^{1}$ Yuan Zhou, ${ }^{1}$ Ming Chen, ${ }^{2}$ and Yichao $W u^{2}$ \\ ${ }^{1}$ School of Environment and Civil Engineering, Jiangnan University, No. 1800, Lihu Avenue, Wuxi 214122, China \\ ${ }^{2}$ Shanghai Open Steel Joist Co. Ltd., No. 86 Maoxing Road Pudong, Shanghai 200000, China \\ Correspondence should be addressed to Zou Yun; zouyun_22@126.com
}

Received 26 October 2018; Revised 10 April 2019; Accepted 14 April 2019; Published 28 May 2019

Academic Editor: Libo Yan

Copyright ( 92019 Chengquan Wang et al. This is an open access article distributed under the Creative Commons Attribution License, which permits unrestricted use, distribution, and reproduction in any medium, provided the original work is properly cited.

\begin{abstract}
Steel-concrete composite (SCC) columns have widely been applied in modern construction industry owing to the composite action between the concrete and the steel. The benefits of SCC columns can be further achieved if the confinement effect of concrete is applied. Therefore, this paper presents an innovative square steel-concrete composite (ISSCC) column made of four steel tubes at the corners and corrugated steel batten plates on all sides. Through the experimental and finite element (FE) numerical simulation calculations, the axial compression performance and seismic performance of the ISSCC column were discussed, and the FE model was verified through experimental results. The seismic performance of the ISSCC column was compared and analyzed with reinforced concrete column under different axial compression ratios. The research showed that FE models can accurately simulate the deformation, stress, and failure states of the ISSCC column under axial pressure and horizontal low cyclic load. Furthermore, the ISSCC column performed good ductility and energy dissipation capacity, and the seismic performance index was better than the reinforced concrete column and had better seismic performance. The results of this study can provide reference for the design and development of the new composite column.
\end{abstract}

\section{Introduction}

With the development of urban construction, the height and span of buildings are increasing, and the loads on beams and columns are also increasing. The structure and components need to have higher bearing capacity, smaller cross section size, better ductility, stronger fire resistance, and good construction convenience to meet the requirements. The steelconcrete composite (SCC) column with high bearing capacity and good ductility has widely been used in the construction of industrial buildings, high-rise buildings, long-span bridges, and transmission towers. One of the most effective SCC columns is a concrete-filled steel tube (CFST) column. The CFST column composes of an empty steel tube filled with concrete, at which both materials sustain together the applied axial load. In recent years, CFST column has widely been used in various building structures and bridges due to good mechanical properties and construction performance [1-4].
However, relevant studies [5-9] showed that, under horizontal cyclic loading, the traditional thin-walled concretefilled steel tube column was prone to local buckling, the postbuckling seismic performance was poor, and the confinement effect of core concrete was not enough. In view of the poor seismic performance of concrete-filled rectangular steel tube column, scholars at home and abroad have done a lot of research, and several concrete-filled rectangular steel tube columns were proposed. Tao et al. [10] proposed the stiffened concrete-filled thin-walled hollow steel structural (HSS) stub column, which can alleviate local buckling and improve the bearing capacity of square and rectangular concrete-filled steel tubular columns, but it has no obvious effect on ductility. Cai et al. [11-20] investigated the steel tube with binding bars, and horizontal restraint rods were installed along the steel tube wall. The research showed that the restraint effect of the steel pipe on the core concrete and the bearing capacity and ductility of the CFST columns have been 
improved. Wang et al. [21] studied a new stiffened concretefilled steel column made of welded channel steels, the research showed that the confinement of the steel tube to the core concrete was obviously strengthened at the corner, and the bearing capacity and ductility of the members were obviously improved. Ding et al. [5] investigated the behavior of steelreinforced concrete-filled square steel tubular stub columns. Liew et al. [6, 7, 9, 22-24] found that adding steel tubular in the concrete-filled steel tubular column can not only improve the fire resistance of the concrete-filled steel tubular column but also improve the bearing capacity and ductility of the column. Tao et al. [10, 25-28] found that the longitudinal stiffening ribs were an effective method to improve the mechanical properties of thin-walled concrete-filled square steel tubular members.

In this paper, an innovative square steel-concrete composite (ISSCC) column made of four steel tubes at the corners and corrugated steel batten plates on all sides was proposed to solve the problems of easy buckling and poor cooperation between steel tube and concrete in the traditional concrete-filled square steel tube columns. The axial compressive and seismic properties of the ISSCC columns were investigated by experiments and FE analysis, which provided references for the design and development of the new composite columns.

\section{Experimental and Finite Element Numerical Analysis on Axial Compression Performance}

2.1. Introduction of ISSCC Column. In this paper, a new type of the steel-concrete composite column was presented and tested under the axial load. The schematic diagram of the ISSCC column is shown in Figure 1, in which the square steel tube is arranged at the four corners of the new composite column and corrugated steel batten plates on all sides, then the concrete is poured in. In the construction of ISSCC columns, the square steel tubes arranged at four corners welded with corrugated steel plates not only can increase the lateral restraint of square steel tubes and improve the lateral stiffness and stability of square steel tubes but also the formed steel tube-panelled space frame will improve the hoop effect on the core concrete, therefore, the cooperative work performance of steel and concrete can be improved. Finally, the static and seismic performances of the ISSCC column will be effectively improved.

The height of the test ISSCC column is $3000 \mathrm{~mm}$, and the photos of the test components are shown in Figure 2. The size of the square steel tube is $75 \times 75 \times 2 \mathrm{~mm}$, and the thickness of corrugated steel batten plate is $2 \mathrm{~mm}$. The design diagrams of the ISSCC column and corrugated steel batten plate are shown in Figures 3 and 4, respectively.

Before compressive experiments of the ISSCC column, the mechanical properties of the concrete and steel were tested. Two types of mild steel were used in this paper, and tensile coupon tests were conducted according to the China National Standard (GB/T 228.1-2010). The obtained yield strength, ultimate tensile strength, elastic module, and Poisson's ratio of steels are listed in Table 1. In addition, the cubic compressive strength of concrete was measured according to the China National Standard (GB/T 500812002). The concrete in the columns were adopted, and their compressive strengths were $42.4 \mathrm{MPa}$.

2.2. Test Setup and Instrumentation. Compressive load on the specimens were applied by a 1000-ton long column testing machine, and the test setup is shown in Figure 5. The loading system adopted the one-time crushing loading method; the load increment of each stage was $50 \mathrm{kN}$, and the duration was 2 minutes. After the column yielded, the displacement increment of each stage was $1 \mathrm{~mm}$. When the buckling deformation of the steel tube was severe and the corner weld of the steel pipe was severely torn, the loading was stopped during the compressive experiments, four linear variable differential transformers (LVDT) were used to record the relative displacement between the top and bottom, steel and concrete strain gauges were attached to the outer surfaces of the column to record the axial and hoop strains, the embedded concrete strain gauges were used to measure the strains of core concrete, and the layout of the strain measuring points is shown in Figure 6.

2.3. Finite Element (FE) Modelling. Although a full-scale test provides an accurate insight into the structural characteristics of ISSCC columns, the experiments are quite expensive and time consuming. Therefore, the systematic development of FE modelling can be utilised for an accurate complementary investigation. Nonlinear FE models of the ISSCC column were developed using ABAQUS.

2.3.1. Element Type and Size. The eight-node reduced integration linear solid elements with three translation degrees of freedom (C3D8R) were utilised for modelling the steel tube, corrugated steel plate, concrete and loading plates [1-4]. Obviously, the thin-walled steel tube used in the ISSCC column buckles locally outwards with the extrusion provided by the filled concrete. The solid elements were effectively found to capture the outer buckling of the thinwalled steel tubes subjected to uniform axial loading [29]. Therefore, the corrugated steel plates were also discretised using the eight-node linear solid elements with three translation degrees of freedom (C3D8R).

The mesh of core concrete and steel tube was refined, and adequate size and number of elements were selected by performing mesh convergence study on some FE models. The mesh convergence study indicated the steel and concrete sections can be meshed with the $15 \mathrm{~mm}$ and $30 \mathrm{~mm}$ element size, respectively. 40908 solid elements were used in the FE model, and the sweep meshing technique was adopted in meshing the FE model; the typical FE mesh diagrams are shown in Figures 7 and 8.

2.3.2. Material Constitutive Relations. The damageplasticity model was used in the FE model to simulate the concrete, and the value of dilation Angle $(\psi)$ was $35^{\circ}$, which was determined by using equation (1). The flow potential eccentricity was taken as the default value of 0.1. Calculated 


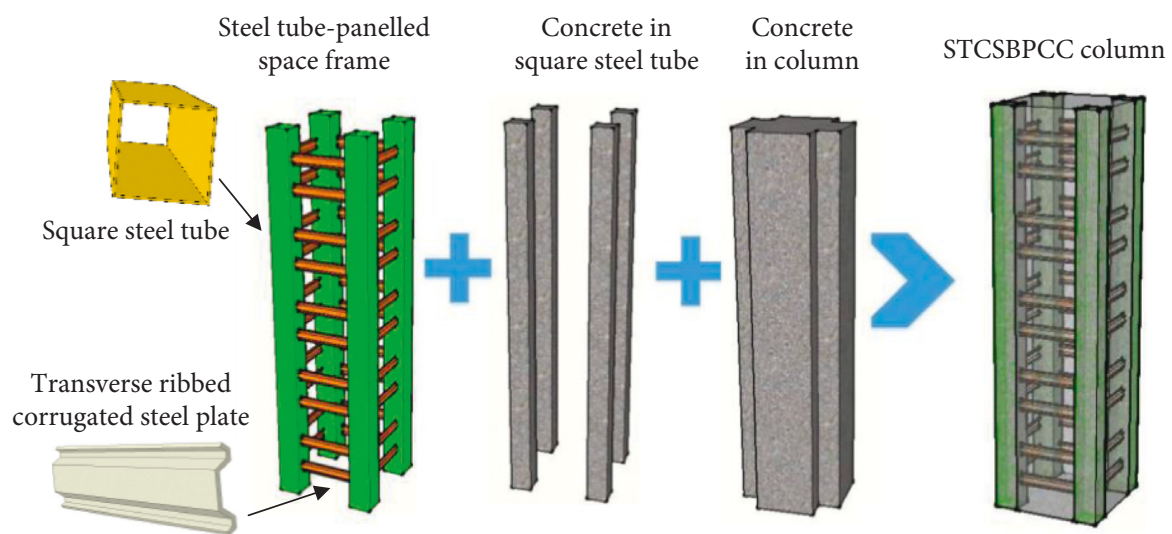

FIgURE 1: Schematic diagram of the composite column.

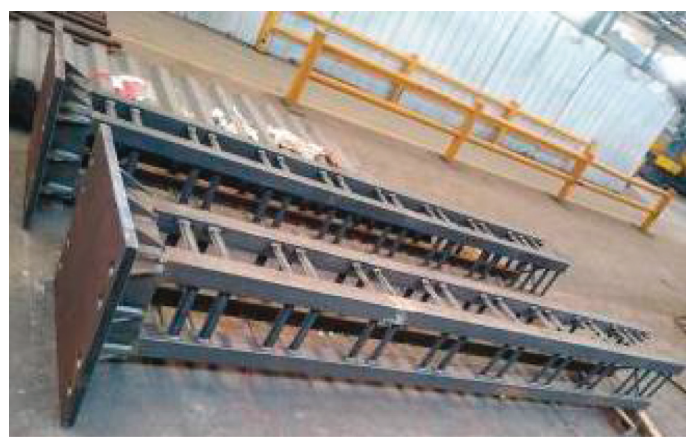

(a)

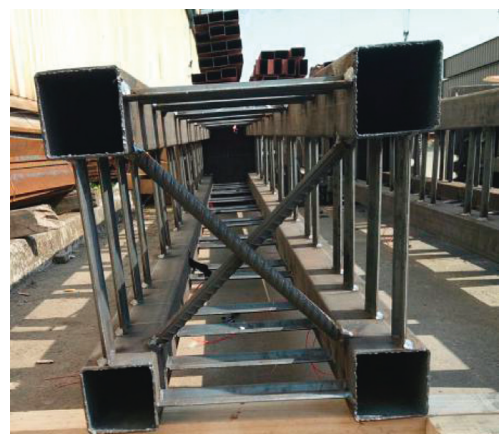

(b)

Figure 2: Test components photos.

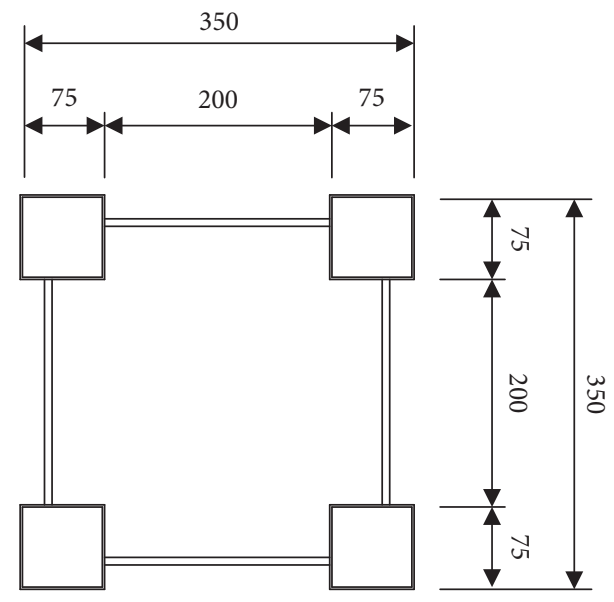

FIGURE 3: Design diagram of the ISSCC column.

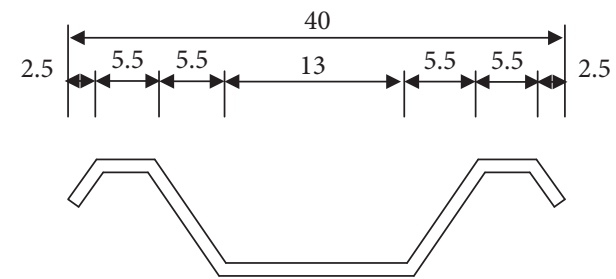

FIGURE 4: Waveform design of the corrugated steel plate.
TABle 1: Properties of steel.

\begin{tabular}{lccccc}
\hline Material & $\begin{array}{c}t \\
(\mathrm{~mm})\end{array}$ & $\begin{array}{c}f_{\mathrm{y}} \\
(\mathrm{MPa})\end{array}$ & $\begin{array}{c}f_{\mathrm{u}} \\
(\mathrm{MPa})\end{array}$ & $E_{\mathrm{s}}(\mathrm{MPa})$ & $v_{\mathrm{s}}$ \\
\hline $\begin{array}{l}\text { Steel tube } \\
\begin{array}{l}\text { Corrugated steel } \\
\text { batten plate }\end{array}\end{array}$ & 2 & 184 & 465 & $2.09 \times 10^{5}$ & 0.292 \\
& & 123 & 383 & $2.10 \times 10^{5}$ & 0.310 \\
\hline
\end{tabular}

by using equation (2), the ratio of the compressive strength under biaxial loading to uniaxial compressive strength $\left(f_{\mathrm{b} 0} / f_{\mathrm{c} 0}\right)$ was 1.16 . Invariable stress ratio $\left(K_{\mathrm{c}}\right)$ was calculated by using equation (3), which was 0.667 , and the viscosity parameter was $0.0005[30,31]$ :

$$
\begin{aligned}
\psi & = \begin{cases}56.3(1-\xi), & \text { for } \xi \leq 0.5, \\
6.672 e^{7.4 /(4.64+\xi)}, & \text { for } \xi>0.5,\end{cases} \\
K_{\mathrm{c}} & =\frac{5.5}{5+2\left(f_{\mathrm{c}}^{\prime}\right)^{0.075},} \\
\frac{f_{\mathrm{b} 0}}{f_{\mathrm{c}}^{\prime}} & =1.5\left(f_{\mathrm{c}}^{\prime}\right)^{-0.075} .
\end{aligned}
$$

The relation model Saenz was used to simulate the concrete uniaxial compression stress and strain relations, which is shown in Figure 9. The constitutive relationship of 


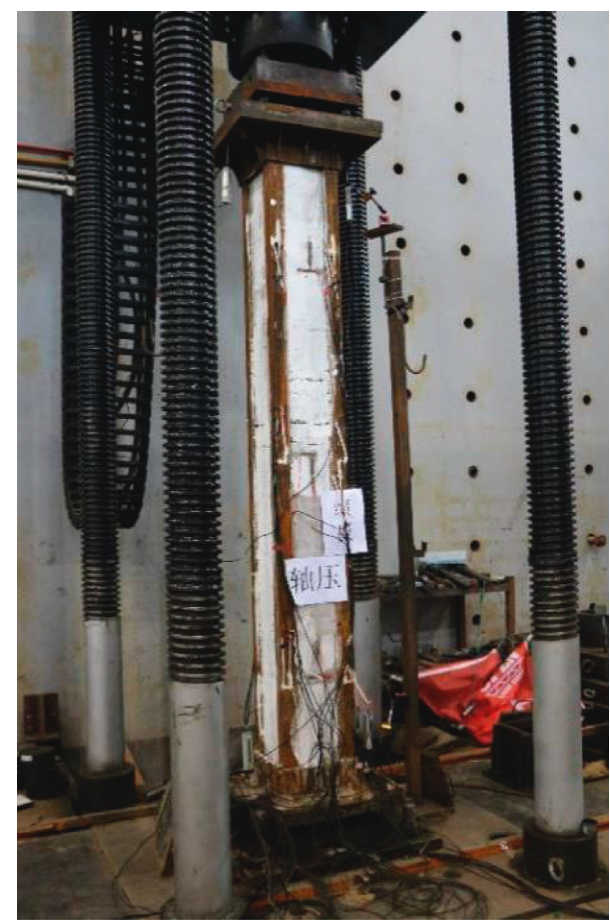

FIgURE 5: Test loading device.

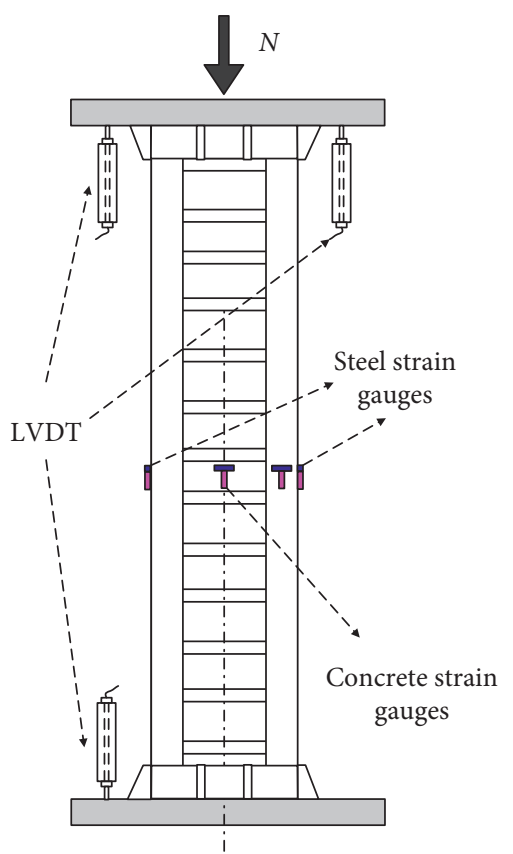

FIGURE 6: Layout of the measuring points.

steel tube and steel rebar is perfectly plastic model, which is shown in Figure 10.

The section of the whole composite column is divided into several parts by using the steel tube and corrugated steel plate. Surface-to-surface contact was usually used for the interaction simulation of the steel tube and concrete, which includes normal contact and tangential slip and a surface-based interaction with hard contact in the normal direction. The Small

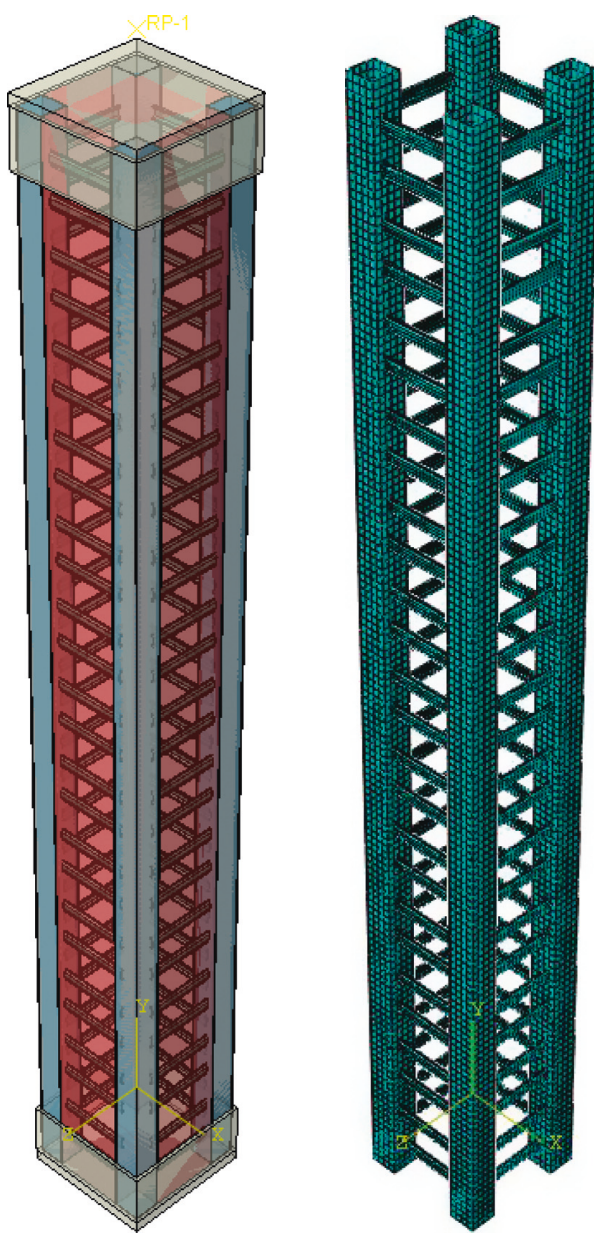

FIgURE 7: Mesh diagram of the FE model.

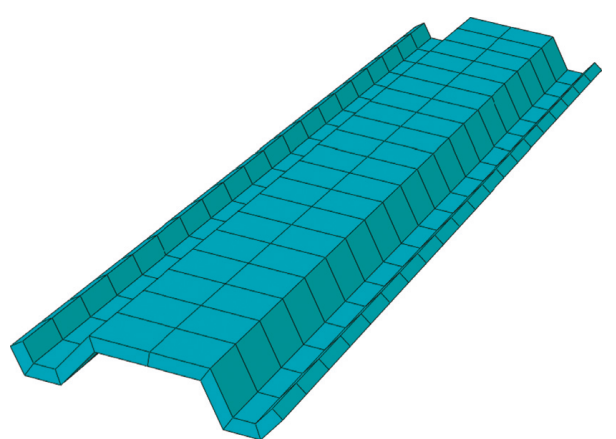

FIgURE 8: Mesh diagram of the corrugated steel plate.

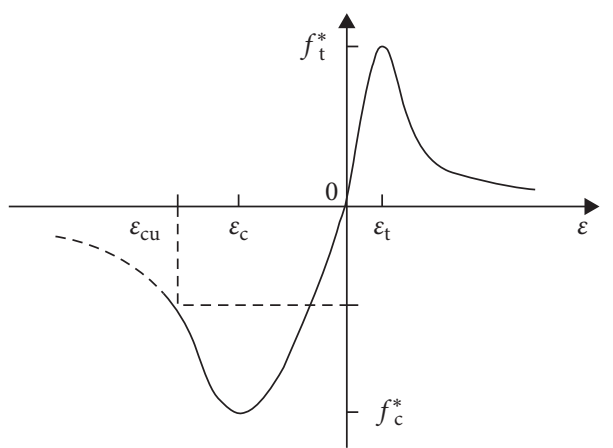

FIGURE 9: Stress-strain relation of concrete. 


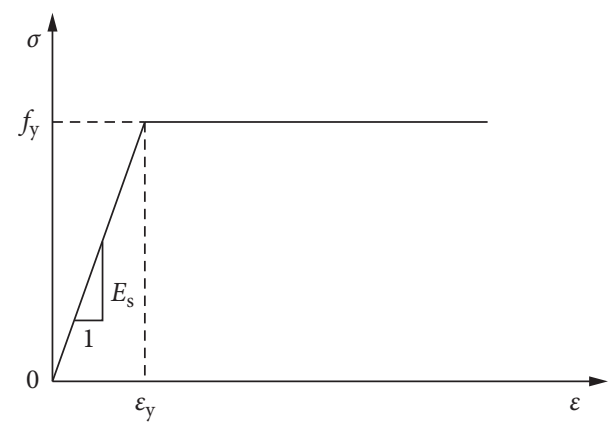

Figure 10: Steel constitutive relation.

sliding and the Coulomb friction coefficient of 0.4 in the tangential direction to the interface is used to simulate the interfacial behavior between steel tube and core concrete [20], in which the sliding formulation is finite sliding. Tie constraint can couple two separate surfaces so that no relative motion occurs between them. In the FE model, the tie option was adopted for the constraint between core concrete, corrugated steel plate section, and the loading plates, which can ensure that the load is applied to the column in the whole loading process. The translational degrees of freedom of all nodes in the loaded steel plate are coupled in the vertical loading direction, and load was applied by means of displacement. Both material and structural nonlinearities were considered, and the static general method was used in the solution process.

2.3.3. Contact Interaction. Numerous investigations have simplified the bond behavior by considering merely the frictional resistance in the FE modelling. Therefore, the surface-to-surface contact interactions were employed in this FE model, on the deformable surfaces of the steel tube and concrete core. The inside surface of octagonal steel sections was defined as master surface, and the outside surface of infilled concrete was assigned as slave surface for the contact algorithm. The interaction between two deformable surfaces in the normal direction was specified by "hard contact." This avoids the surface penetration in compression and allows the separation in tension. The tangential behavior of contacted surfaces was specified by using the Coulomb friction model. The friction coefficient $(\mu)$ of 0.3 was utilised in this study [29]. The embedded region method was attached to simulate the relationship between corrugated steel plate and concrete, which is usually designated to deal with one or a group of cells located in other units arrested problems in ABAQUS.

2.3.4. Load and Boundary Conditions. Two loading end plates were included in the ISSCC column FE model, and the reference points coupled with the surface of loading end plates were assigned to control the displacement-controlled loads and degrees of freedom. The degree of freedom at the bottom reference point was restrained in translations, and the top reference point was allowed to displace in the loading direction [21]. Both material and structural nonlinearities were considered, and the static general method was used in the solution process.
2.4. Verification of the FE Model under the Axial Pressure Loading. The accuracy and efficiency of the developed FE model was demonstrated by making comparison with the experimental results. The load-deflection curves of ISSCC columns obtained from FE modelling were compared with the experimental results, which is shown in Figure 11.

It can be seen from Figure 11 that the FE model result is in good agreement with the experimental result. Because the loading surface of test component was not smooth, the two curves have great difference in the initial stage. The displacement-load curves of composite columns were in the form of threefold line. At the beginning, the failure of concrete was limited, and the bearing capacity of columns was improved because of the restraint effect of a rectangular steel tube and steel tube-panelled space frame on concrete. With the increase of the vertical load, the restraint effect of corrugated plates cannot prevent the transverse deformation of core concrete, the corrugated plate yielded, and the outer concrete cracked. After loading to the ultimate bearing capacity, the square steel tubes yielded, the core concrete crushed, and the corrugated plates deflected under the push of the core concrete; then the bearing capacity of the composite column decreased; and the members were destroyed. The failure state of the test column is shown in Figure 12.

The reason for the difference between the two curves was that the tie constraint between the corrugated plate and concrete cannot simulate the separation of interfaces, and the material properties of core concrete were too ideal in the FE model. In conclusion, the FE model in this paper can accurately simulate the stress and deformation of ISSCC columns from the elastic stage, the elastic-plastic stage, and the plastic stage, and the FE model can be used for the seismic performance analysis in upcoming section.

2.5. Composite Action Analysis. In order to obtain a deeper understanding on the mechanical performance of ISSCC columns under axial loading, the composite action between concrete-filled steel tube, steel tube-panelled space frame, and core concrete is conducted in this section. The longitudinal stress contours of the section at critical points are shown in Figure 13.

The distribution and development of the longitudinal stresses of concrete in the middle cross section of the ISSCC columns in different loading stages are presented in Figure 14. It can be seen that the confinement effect of the concrete in the square steel tube was significant, and the steel tube-panelled space frame can constrain the concrete on the edge, in which the maximum amplification factor was 1.26. In general, the confinement effect was significant in ISSCC columns, and the axial bearing capacity of the column was improved.

\section{FE Numerical Analysis on Seismic Performance}

3.1. FE Modelling for Seismic Analysis. In this paper, the pseudostatic test method was adopted for the numerical simulation calculation of the ISSCC columns under low cyclic loading. The basic principle is to apply constant axial 


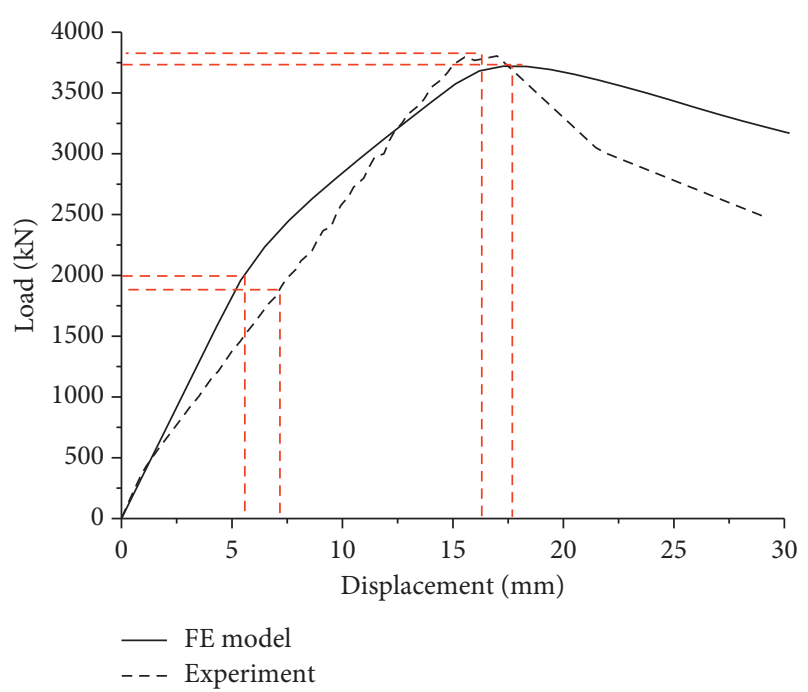

Figure 11: Comparison of experimental and FE modelling results.

force and low cyclic repeated horizontal load on the top of the column. During the test, the displacement value of the component is controlled so that the component can control the loading step of the displacement in each loading displacement, and the loading speed and the loading amount of each step of the displacement are adjusted so that the specimen is loaded and unloaded repeatedly in both positive and negative directions, which can simulate the stress of the specimen in the earthquake. In order to compare the seismic performance, the FE models of ISSCC columns and reinforced concrete $(\mathrm{RC})$ columns with a shear span ratio of 1.5 were established, which are shown in Figures 15 and 16.

As shown in Figure 15, a rigid bottom beam was established at the bottom of the columns, and the three translational degrees of freedom of the bottom beam were constrained. The loaded steel plates were set at the top of the columns to avoid the lateral instability and local failure, and the lateral displacement constraint was applied. The test load was applied in two steps, the first step was to apply vertical axial load to the top of the column to the corresponding axial compression ratio, and the vertical axial load value was derived from equation (4). The second step was to apply horizontal displacement to the reference point, which were coupled with the translational degrees of freedom of all nodes on the column top:

$$
N=n_{\mathrm{s}} \cdot\left(A_{\mathrm{s}} \cdot f_{\mathrm{y}}+A_{\mathrm{c}} \cdot f_{\mathrm{c}}\right),
$$

where $n_{\mathrm{s}}$ is the axial compression ratio; $A_{\mathrm{s}}$ and $A_{\mathrm{c}}$ are the section area of steel and concrete, respectively; and $f_{\mathrm{y}}$ and $f_{\mathrm{c}}$ are the yield strength of steel and compressive strength of concrete, respectively.

The material properties and contact relations of $\mathrm{FE}$ models in this section are the same as those in Section 2.3, and the loading system of the horizontal displacement of the column top is shown in Figure 17.

3.2. Hysteretic Analysis. The load-displacement hysteresis curves of the columns are the concentrated reflection of the bearing capacity and deformation of the specimens under the earthquake. The results of the hysteresis curves of the FE models of the ISSCC column and reinforced concrete column are shown in Figures 18 and 19.

As can be seen from Figure 18, at the initial stage, the hysteretic curve was basically a straight line across the origin, the load-displacement curves of loading and unloading coincided basically, the area of hysteretic loop was almost zero, and the ISSCC column was in the elastic stage. With the increase of cyclic displacement, the concrete on the surface of the composite column cracked, the steel tube buckled, the column entered the stage of elastic-plastic work, the plastic deformation of the column accumulated continuously, the increase of the horizontal load of the specimen slowed down, the stiffness of the composite column degenerated, and the residual deformation increased gradually. It can be seen from Figure 18 that the hysteretic curves of ISSCC columns were plump and were shuttle shaped. By analyzing the shape characteristics of hysteretic curves, it can be found that the position marked by point A in Figure 18(a) was the yield load of ISSCC column, and then the concrete on the surface of column bottom cracked under the cycle loading. Point B represented the ultimate horizontal bearing capacity of the column, after which the steel plate at the bottom of the tube yielded. At $\mathrm{D}$ point, buckling deformation occurred at the bottom of the square steel tubes, the restraint effect of the steel tube-panelled space frame on the core concrete was weakened, the corrugated plates were pushed outward under the extrusion of the core concrete; under the final displacement, the concrete crushed and the column was destroyed. The ISSCC columns with an axial compression ratio $\left(n_{\mathrm{s}}\right)$ of 0.4 and 0.6 were compared and analyzed, and the FE model was S1 and S2, respectively. It can be seen that with the increase of axial compression ratio, the horizontal stiffness and bearing capacity of columns increased. For example, when the horizontal displacement $\left(\Delta_{\mathrm{s}}\right)$ was $0.9 \mathrm{~mm}$, the load $F_{\mathrm{s} 1}=237.15 \mathrm{kN}$ and $F_{\mathrm{s} 2}=249.69 \mathrm{kN}$, and when $\Delta s=2.4 \mathrm{~mm}, F_{\mathrm{s} 1}=363.93 \mathrm{kN}$ and $F_{\mathrm{s} 2}=386.66 \mathrm{kN}$; $F_{\mathrm{s} 2} / F_{\mathrm{s} 1}=1.06$. However, the hysteretic curve of $\mathrm{S} 2$ was not as full as that of S1. It can be concluded that the increase of the axial compression ratio will reduce the energy dissipation capacity of ISSCC columns.

Compared with the ISSCC column, the horizontal bearing capacity of the RC column was higher in the elastic stage. Figure 19 shows that after reaching the ultimate load point $\mathrm{B}$, the RC columns suffered serious shear failure and the hysteretic curve dropped rapidly, which was brittle failure. Furthermore, with the increase of the axial compression ratio, the failure of the RC column was more serious, the residual bearing capacity was lower, the area enclosed by the hysteretic curve decreased, and the energy dissipation capacity of the RC column decreased. However, the ISSCC column with a shear span ratio of 1.5 still had high bearing capacity over the ultimate load. Under the condition of an axial compression ratio of 0.6 , the ISSCC column can still maintain good ductility and energy dissipation capacity, while the RC column suffered serious shear failure and collapsed, which indicated a poor energy dissipation capacity. At the last loading cycle, the residual bearing capacity 


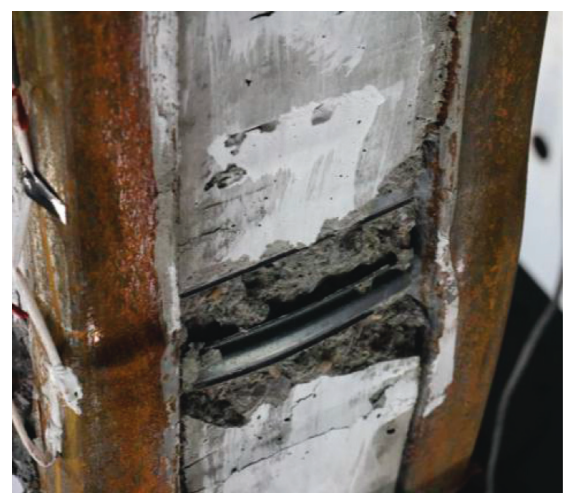

(a)

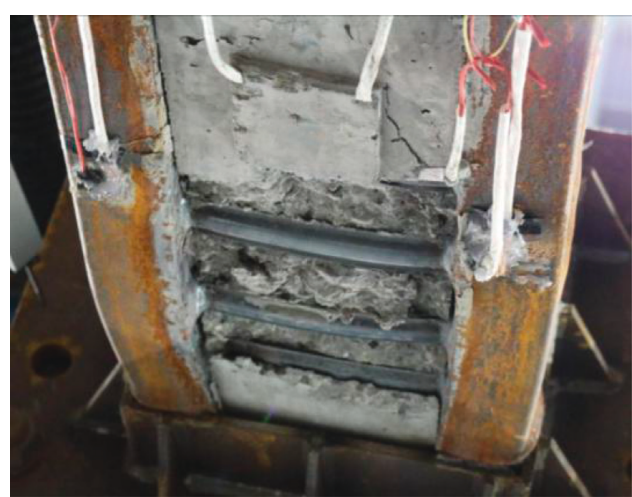

(b)

Figure 12: Failure state and crack distribution of the specimen.

S, S22

(Avg: 75\%)

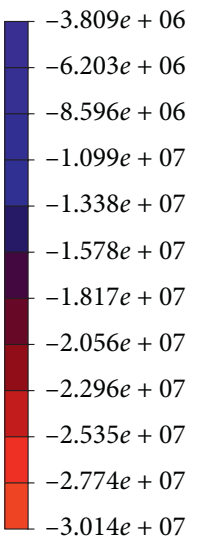

$-3.014 e+07$
S, S22

(Avg: 75\%)

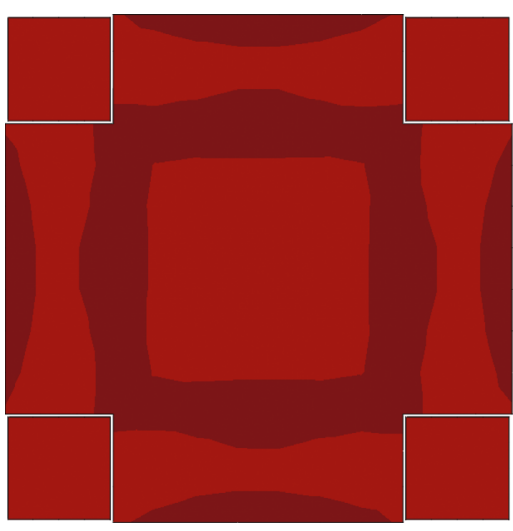

(a)

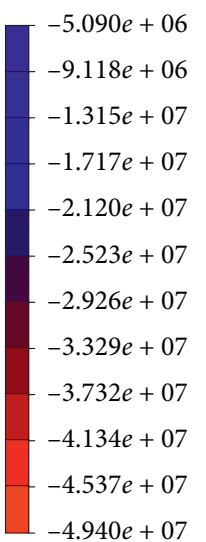

$-4.940 e+07$

S, S22

(Avg: 75\%)

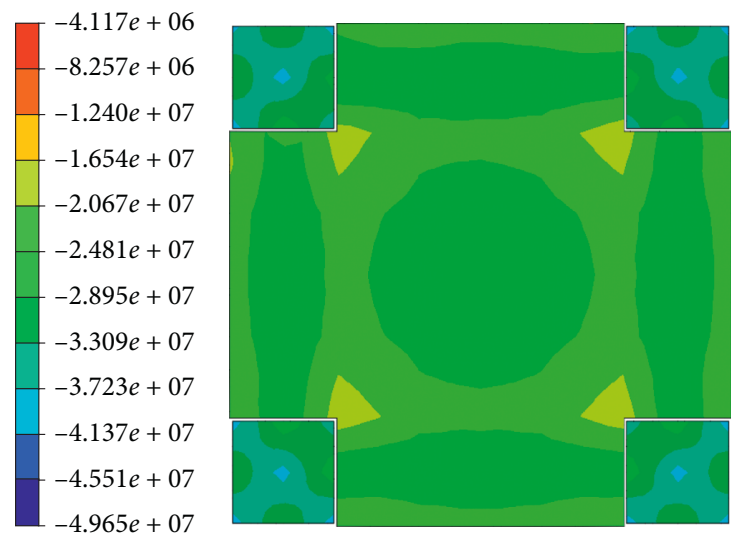

(c)

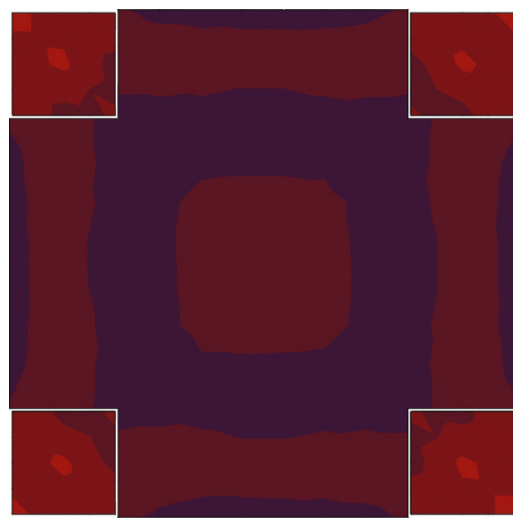

(b) 


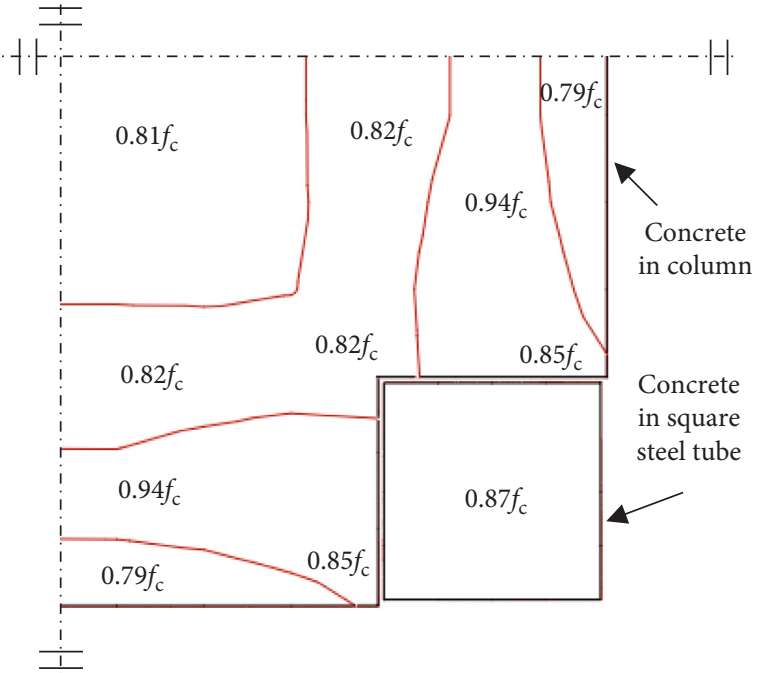

(a)

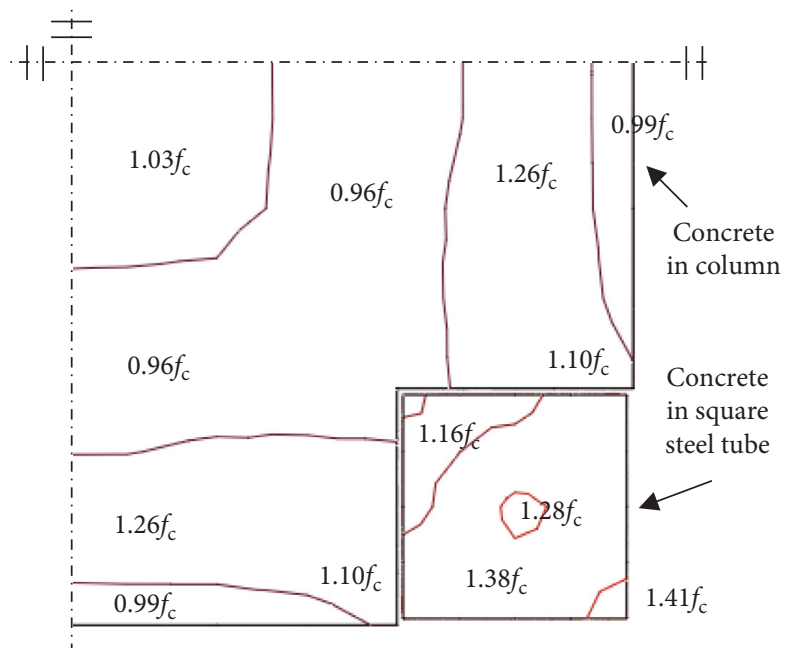

(b)

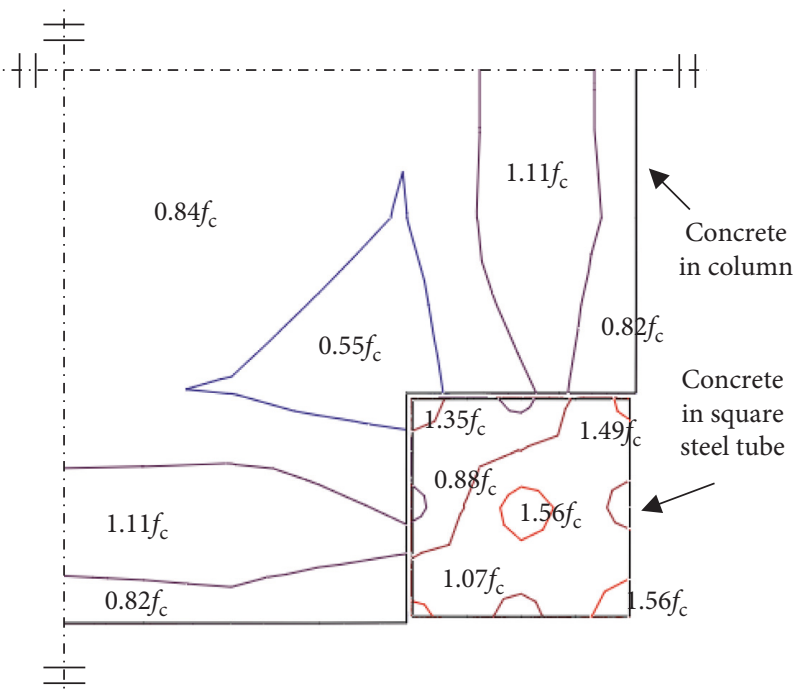

(c)

FIGURE 14: Longitudinal concrete stress distribution in midsections of the ISSCC column. Stress contours under (a) the yield load, (b) the ultimate load, and (c) the ultimate load of $85 \%$.

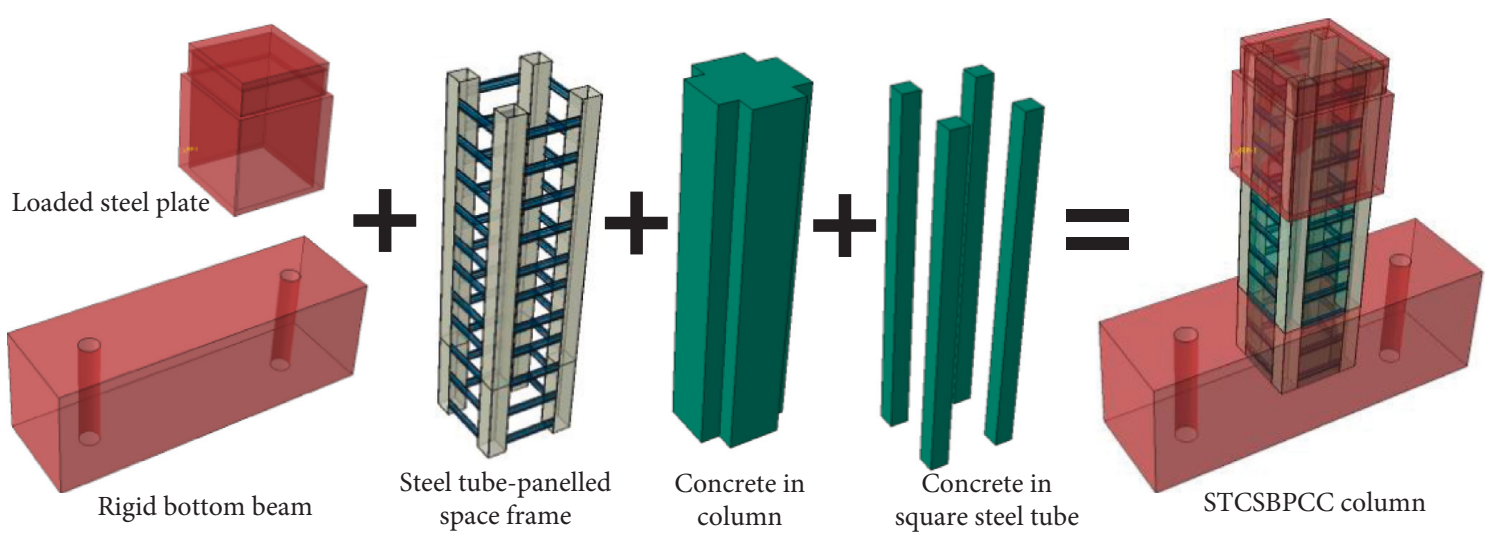

(a)

Figure 15: Continued. 


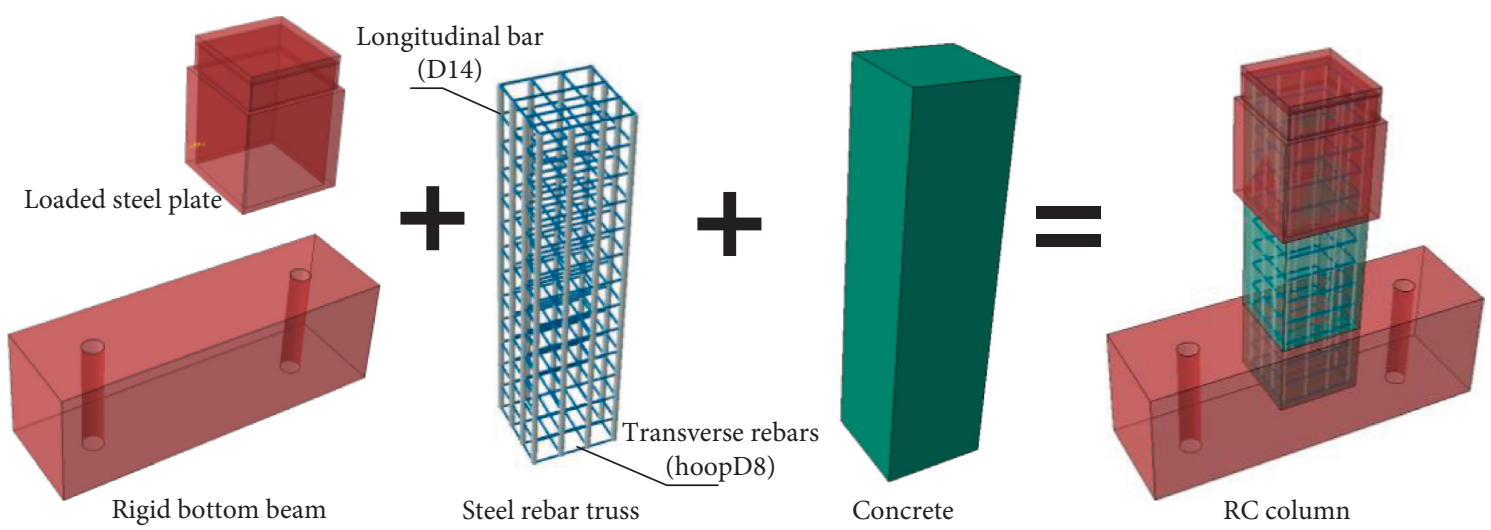

(b)

Figure 15: Finite element models of hysteretic analysis. (a) ISSCC column. (b) RC column.

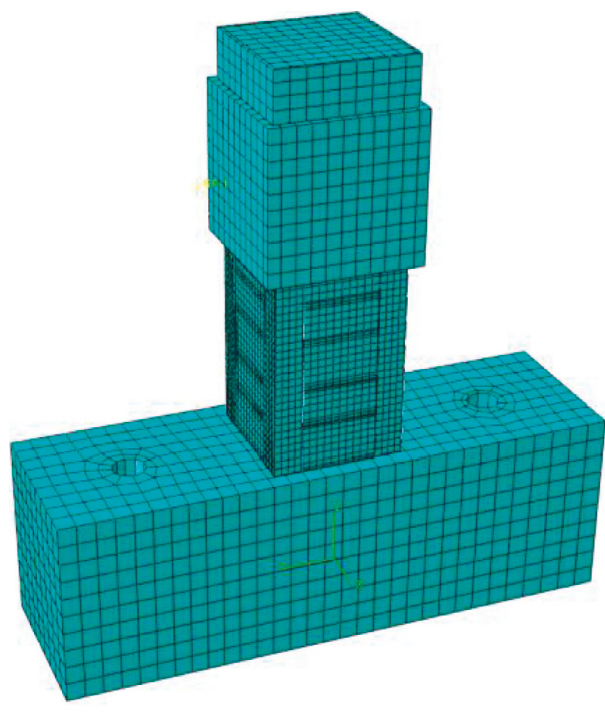

(a)

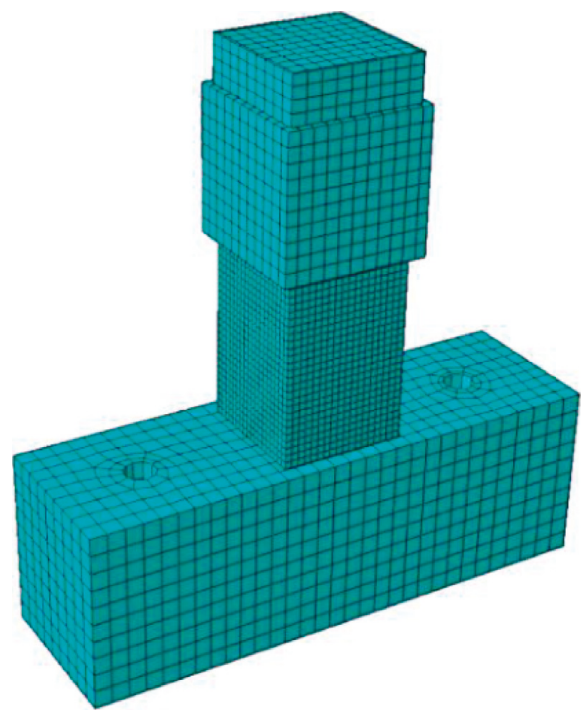

(b)

FIGURE 16: FE models of hysteretic analysis. (a) ISSCC column. (b) RC column.

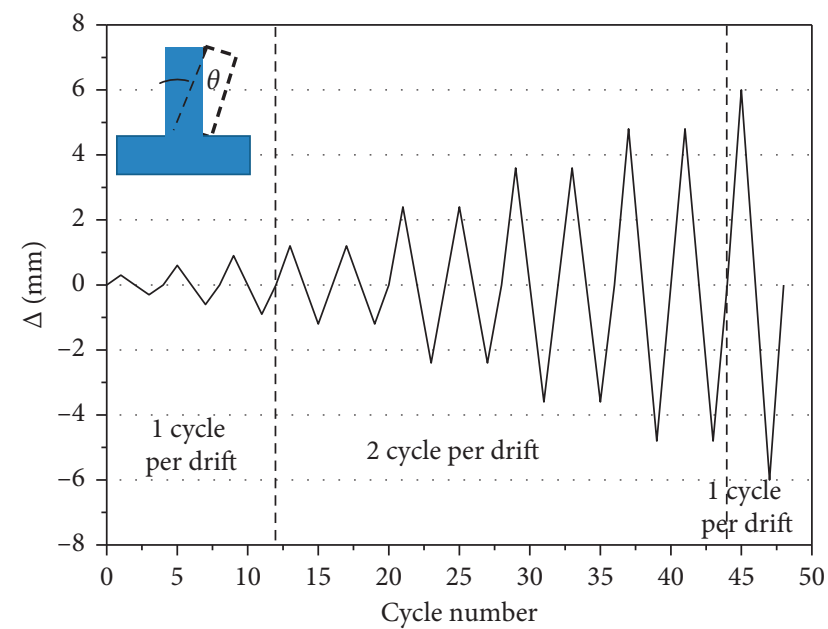

Figure 17: The loading system.
3.3. Deformation Behaviors Analysis. The distribution characteristics of equivalent plastic strain (PEEQ) of the ISSCC column and RC column under low cyclic loading are shown in Figure 20, and the axial compression ratio of which was 0.4 .

According to the studies of Lubliner et al. [32], when the tensile plastic strain at a point is greater than zero and the maximum principal plastic strain is positive, the initial crack generates at this point, and the normal vector of the crack surface parallels to the direction of the maximum principal plastic strain. The equivalent plastic strain of the concrete in Figure 20 can be used to analyze the distribution of the cracks.

3.4. Skeleton Curve Analysis. The skeleton curve is the trajectory where the load-deformation curve reaches the maximum load point in each cycle of the hysteretic curve. 


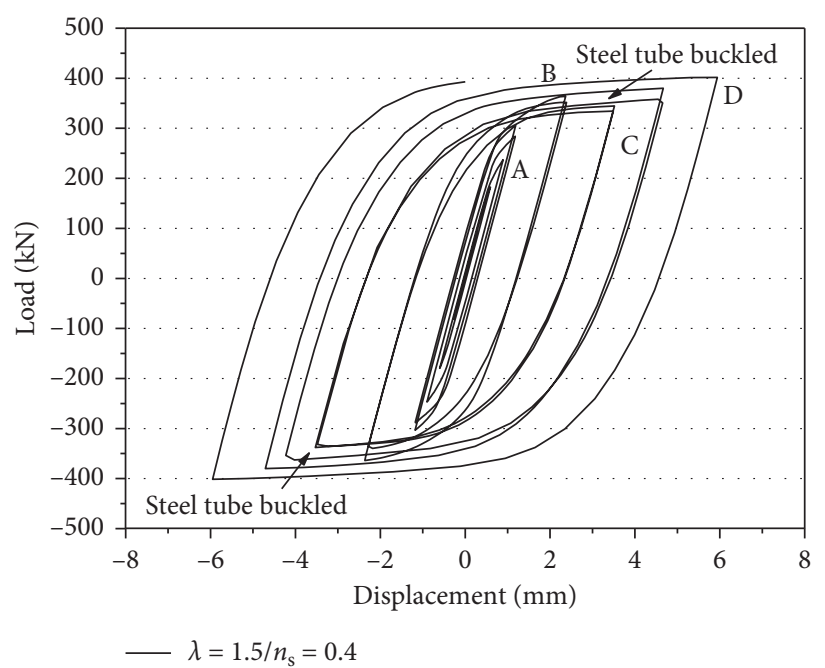

(a)

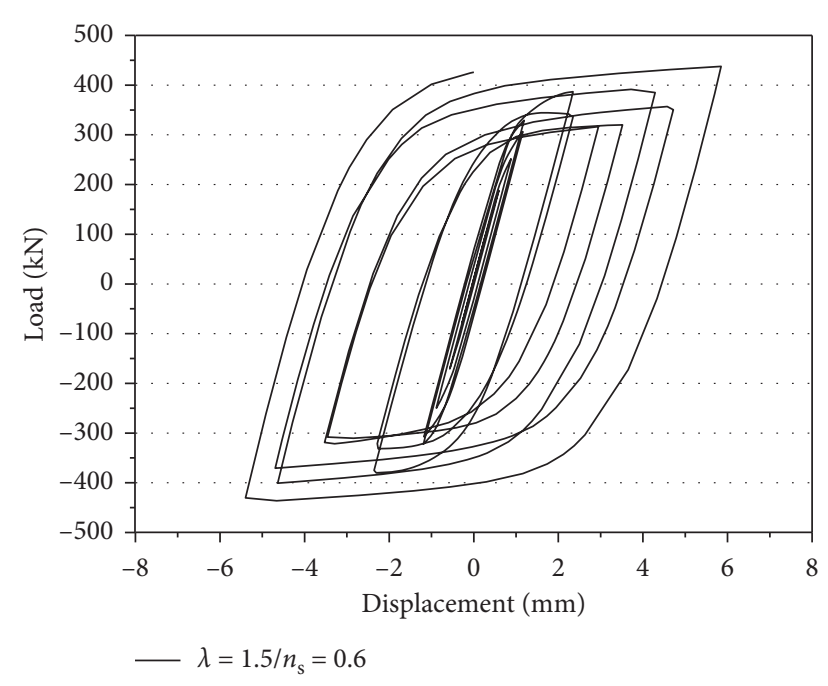

(b)

FIGURE 18: Hysteretic curves of the ISSCC columns. (a) $n_{\mathrm{s}}=0.4$. (b) $n_{\mathrm{s}}=0.6$.

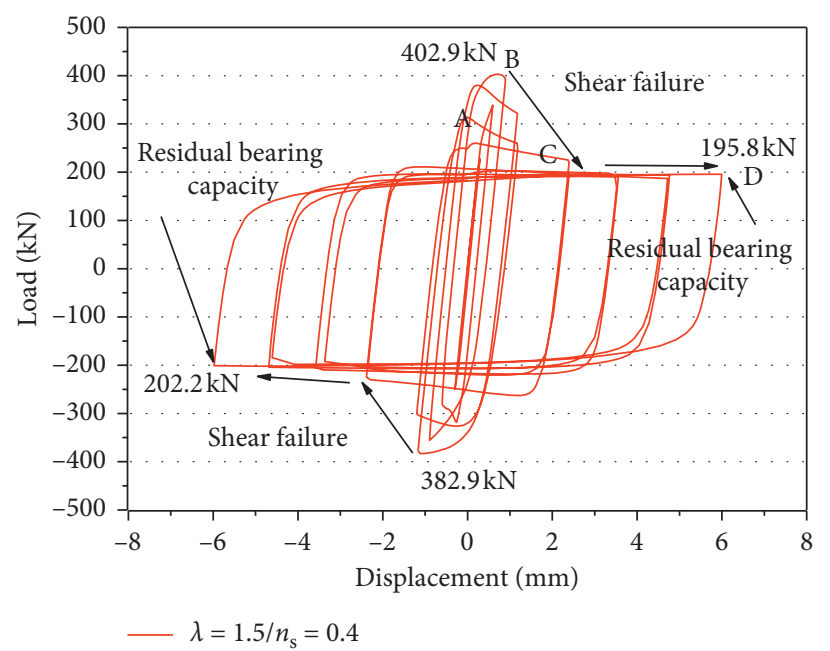

(a)

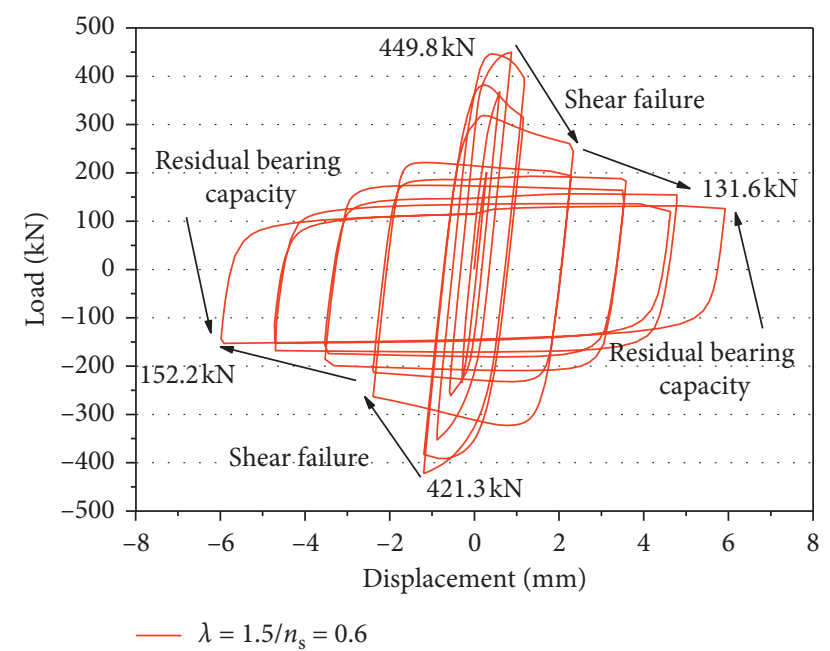

(b)

Figure 19: Hysteretic curves of the RC columns. (a) $n_{\mathrm{s}}=0.4$. (b) $n_{\mathrm{s}}=0.6$.

The skeleton curve can be used to qualitatively compare and measure the seismic performance of structural specimens. In order to analyze the influence of axial compression ratio on the seismic behavior of ISSCC columns and RC columns, the skeleton curves under different axial compression ratios are shown in Figures 21 and 22 .

It can be seen from Figure 21, the variation trend of the ISSCC columns skeleton curve was approximately S-shaped. The mechanical characteristics of the model under low cyclic loading can be divided into elastic stage, plastic stage, and failure stage. The axial compression ratio had little effect on the elastic stage stiffness of the steel tube-corrugated concrete composite columns. With the increase of the axial compression ratio, the vertical stress of the core concrete in the composite columns was increased to a certain extent, resulting in a slight increase in the flexural stiffness of the elastic stage and an increase in the load corresponding to the same displacement. The skeleton curve of the ISSCC column showed a slow downward trend after reaching the ultimate bearing capacity, and the downward trend of bearing capacity was slightly accelerated with the increase of the axial compression ratio. The skeleton curves of the RC column are presented in Figure 22, which shows that the axial compression ratio had the same effect on the RC column in the elastic stage. When the axial compression ratio was 0.4 , the ultimate load and corresponding displacement of the skeleton curve were $401.67 \mathrm{kN}$ and $0.79 \mathrm{~mm}$, respectively. When $n_{\mathrm{s}}=0.6$, the ultimate load and corresponding displacement were $447.26 \mathrm{kN}$ and $0.77 \mathrm{~mm}$, respectively.

Comparing the skeleton curves of RC columns and composite columns, it can be found that the RC column 
PEEQ

(Avg: $75 \%$ )

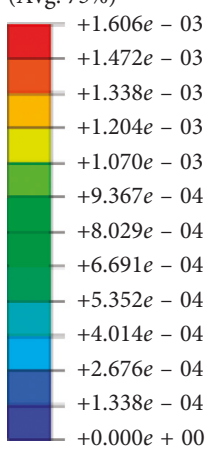

PEEQ

(Avg: 75\%)

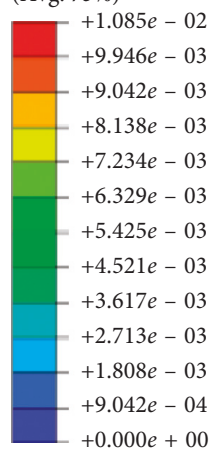

PEEQ

(Avg: $75 \%$ )
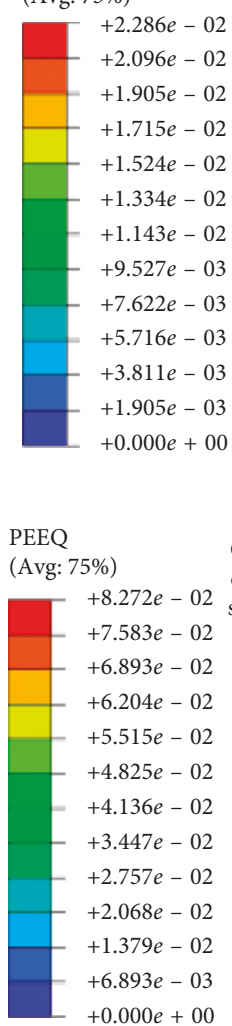

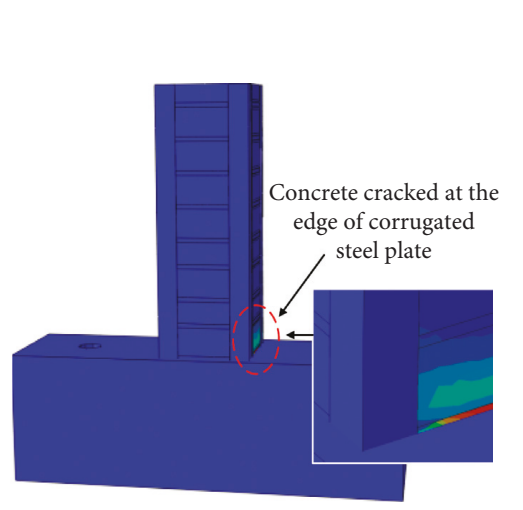

PEEQ

(Avg: 75\%)

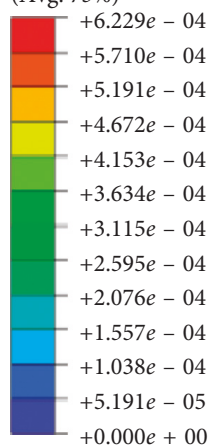

(a)

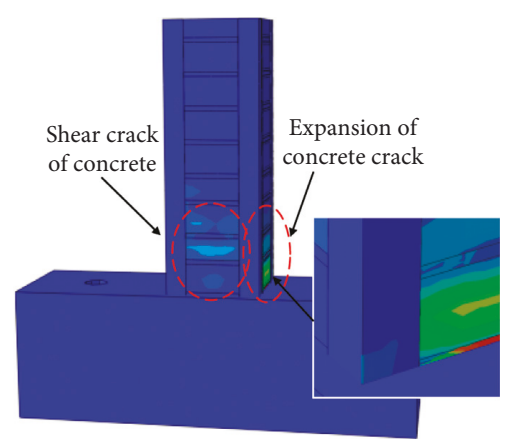

PEEQ

(Avg: $75 \%)$
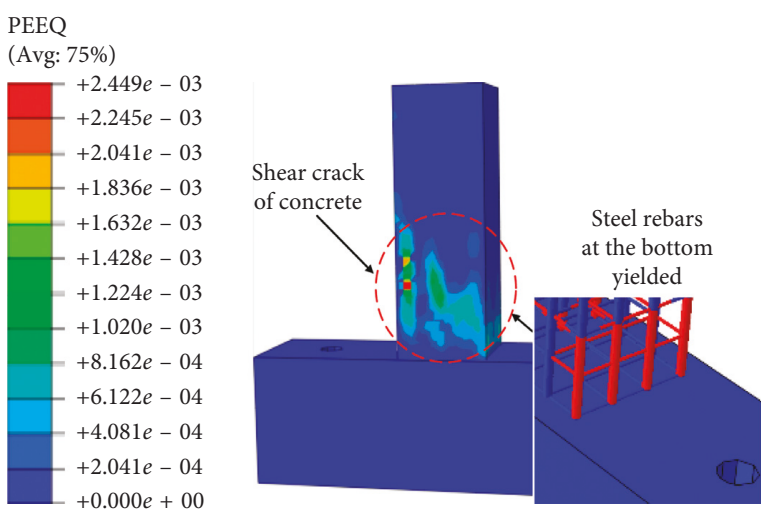

(b)

\section{PEEQ}

(Avg: $75 \%$ )

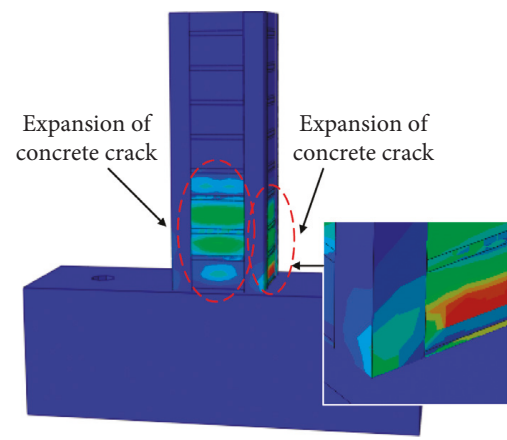

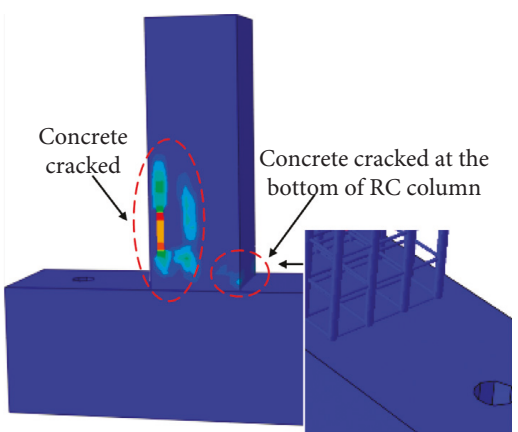

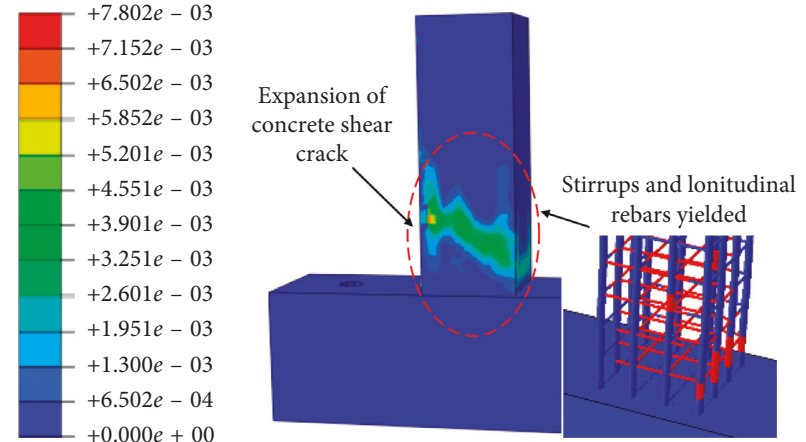

(c)

Combined failure $\quad$ PEEQ

of the buckling of

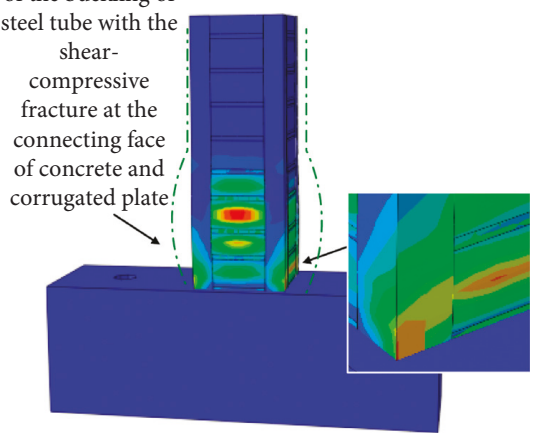

(Avg: 75\%)

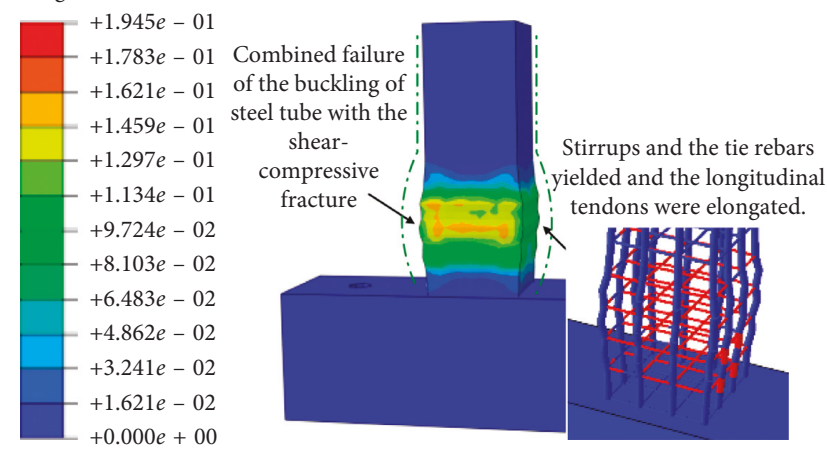

(d)

Figure 20: Strain contours and failure modes of ISSCC columns and RC columns. (a) Point A. (b) Point B. (c) Point C. (d) Point D. 


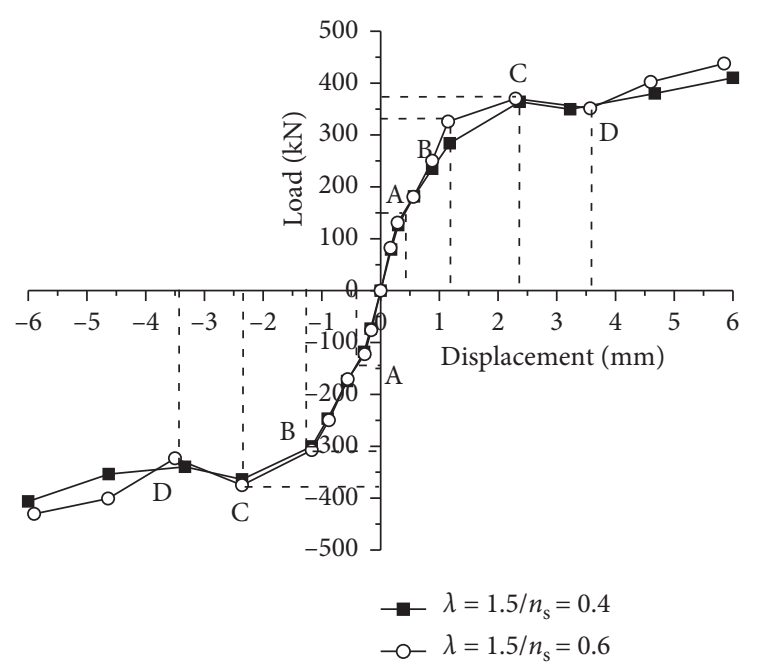

FIGURE 21: Skeleton curves of ISSCC columns under different axial compression ratios.

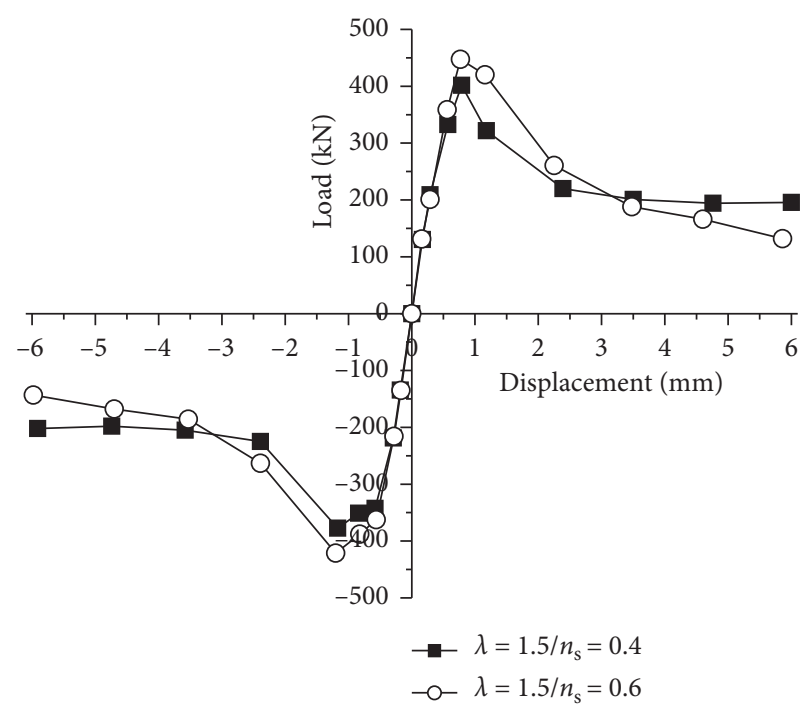

FIGURE 22: Skeleton curves of the RC columns under different axial compression ratios.

skeleton curve descended very steeply after reaching the peak bearing capacity, a sharp angle formed at the peak point, and the ductility was poor. Moreover, the larger the axial compression ratio, the faster the bearing capacity of the RC column decreased. However, the concrete-filled steel tube and the steel tube-panelled space frame in the ISSCC column can form multiple constraints on the concrete so that ISSCC columns had good ductility and stability. The failure of the core concrete under the constraints was also alleviated, and the increase of the axial compression ratio had little effect on later bearing capacity and failure of the ISSCC column.

3.5. Stiffness Degradation Analysis. The average stiffness $K_{j}$ under the same displacement was used to describe the

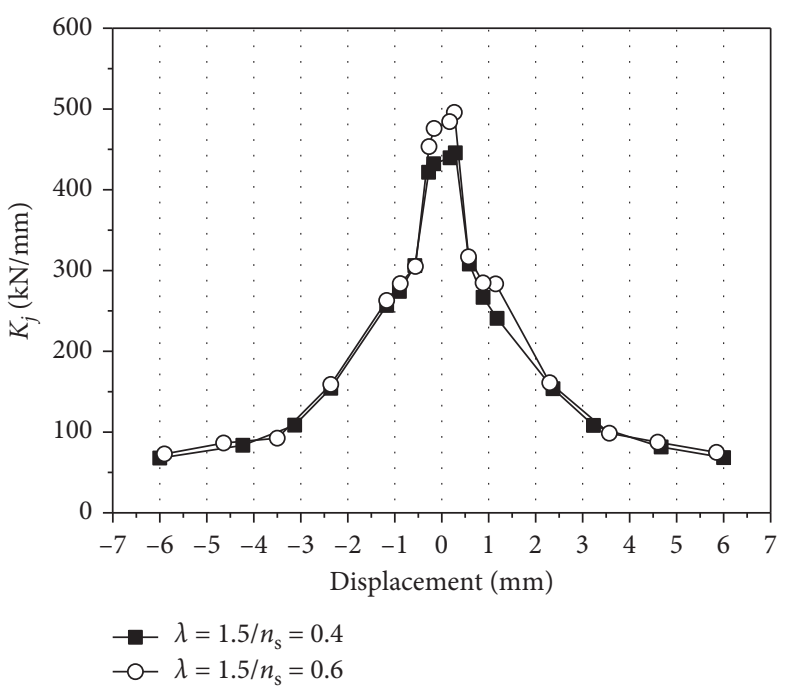

Figure 23: Stiffness degradation curves of the ISSCC columns under different axial compression ratios.

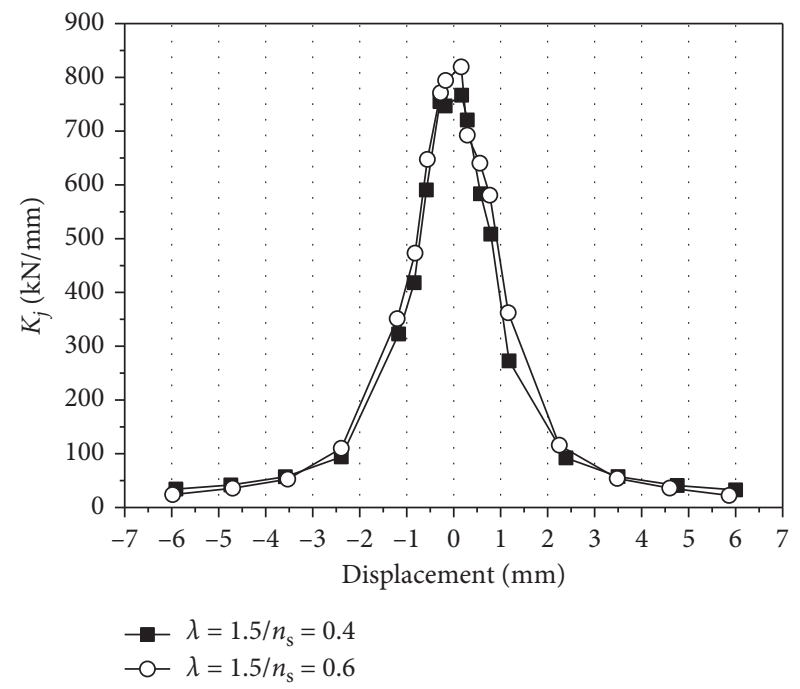

FIgURE 24: Stiffness degradation curves of the RC columns under different axial compression ratios.

stiffness degradation. The expression can be written as follows:

$$
K_{j}=\frac{P_{j}}{\Delta_{j}}
$$

where $P_{j}$ is the average value of the peak load under the $j$ th stage loading and $\Delta_{j}$ is the average value of the deformation corresponding to the peak load.

The stiffness degradation curves of ISSCC columns and RC columns under low-cyclic loads are shown in Figures 23 and 24, respectively. It can be seen from the diagram that the lateral stiffness of the specimens increased slightly with the increase of the axial compression ratio at the initial stage of loading, and the stiffness degradation rate of the specimens with different axial compression ratio were basically the 


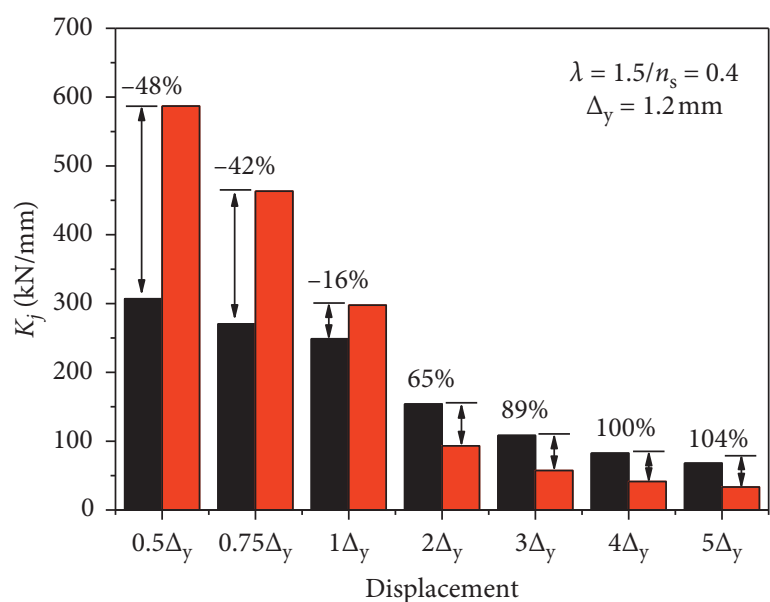

STCSBPCC $\mathrm{RC}$

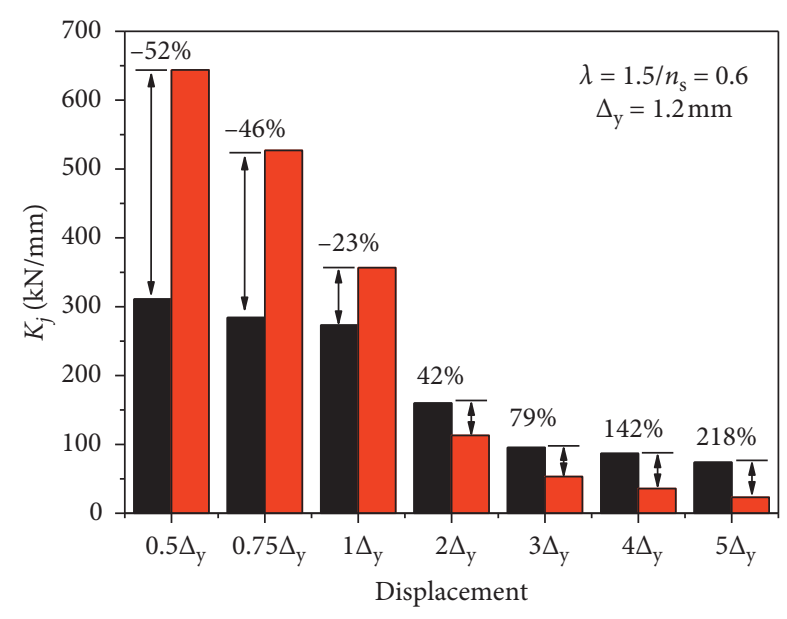

STCSBPCC $\mathrm{RC}$

(a)

(b)

FIGURE 25: Stiffness columnar analysis diagram. (a) $n_{\mathrm{s}}=0.4$. (b) $n_{\mathrm{s}}=0.6$.

same for the same type of columns. Although the initial stiffness of the RC column was larger than that of composite columns, after reaching the ultimate load, stiffness of the RC columns decreased faster and the final stiffness was smaller than that of the ISSCC column. Under the higher axial compression ratio, the $\mathrm{RC}$ column had worse ductility at later stage and lower stiffness. The residual stiffness of the RC column was $23.95 \mathrm{kN} / \mathrm{mm}$, and that of the ISSCC column was $68.37 \mathrm{kN} / \mathrm{mm}$, which is 2.85 times that of the RC column.

In order to visually compare the stiffness changes of ISSCC columns and RC columns under low cyclic loading, a stiffness columnar analysis diagram is presented in Figure 25. As shown in Figure 25, the stiffness of the ISSCC column changed smoothly after failure, which shows good ductility, and the residual stiffness of the ISSCC column was much greater than that of RC columns at the later stage. Furthermore, the increase of the axial compression ratio had little effect on the stiffness degradation and residual stiffness of the ISSCC column.

\section{Conclusion}

In this paper, the axial compression and seismic performance of a new type of prefabricated steel tube-corrugated steel batten concrete composite column were revealed by experiment and finite element numerical simulation analysis. The following conclusions can be derived from the study conducted in this paper:

(1) The steel tube-panelled space frame and four concrete-filled steel tubes in the ISSCC column can effectively constrain the concrete on the edge, and the confinement effect is significant.

(2) The finite element model in this paper can accurately simulate the deformation, stress, and failure state of ISSCC columns under axial pressure and horizontal low cycle cyclic load, which are in good agreement with the experimental results.

(3) Compared with RC columns, ISSCC columns have better ductility and energy dissipation capacity and have higher residual stiffness and bearing capacity.

\section{Data Availability}

All data included in this study are available upon request by contact with the corresponding author.

\section{Conflicts of Interest}

The authors have no conflicts of interest to declare.

\section{Acknowledgments}

We gratefully acknowledge the support from the Fundamental Research Funds for the Central Universities (JUSRP11819), Natural Science Foundation of Jiangsu Province (BK20180623), National Natural Science Foundation of China (51378240), 2018 Science and Technology Department's Social Development Project (BE2018625), and 2015 Jiangsu Provincial Building Energy Saving and Construction Industry Science and Technology Project.

\section{References}

[1] Y. Guo and Y. Zhang, "Comparative study of CFRP-confined CFST stub columns under axial compression," Advances in Civil Engineering, vol. 2018, Article ID 7109061, 8 pages, 2018.

[2] S. İpek and E. M. Güneyisi, "Ultimate axial strength of concrete-filled double skin steel tubular column sections," Advances in Civil Engineering, vol. 2019, Article ID 6493037, 19 pages, 2019.

[3] Y. Lu, T. Zhu, S. Li, W. Li, and N. Li, "Axial behaviour of slender RC circular columns strengthened with circular CFST 
jackets," Advances in Civil Engineering, vol. 2018, Article ID 7923575, 11 pages, 2018.

[4] B. Xu, F. Wu, and G. Xu, "Mechanism study on the axial compressive performance of short square CFST columns with different stiffeners," Advances in Civil Engineering, vol. 2018, Article ID 9109371, 10 pages, 2018.

[5] F.-X. Ding, L. Fu, X.-M. Liu, and J. Liu, "Mechanical performances of track-shaped rebar stiffened concrete-filled steel tubular (SCFRT) stub columns under axial compression," Thin-Walled Structures, vol. 99, pp. 168-181, 2016.

[6] M. Elchalakani, M. F. Hassanein, A. Karrech, and B. Yang, "Experimental investigation of rubberised concrete-filled double skin square tubular columns under axial compression," Engineering Structures, vol. 171, pp. 730-746, 2018.

[7] B. Shekastehband, S. Mohammadbagheri, and A. Taromi, "Seismic behavior of stiffened concrete-filled double-skin tubular columns," Steel and Composite Structures, vol. 27, no. 5, pp. 577-598, 2018.

[8] Y. Wang, Y. Yang, and S. Zhang, "Static behaviors of reinforcement-stiffened square concrete-filled steel tubular columns," Thin-Walled Structures, vol. 58, pp. 18-31, 2012.

[9] X. Zhou, Y. Liu, L. Jiang, and N. Zhang, "Review on mechanical behavior research of concrete filled rectangular hollow section tube stiffened with PBL," China Journal of Highway and Transport, vol. 30, no. 11, pp. 45-62, 2017.

[10] Z. Tao, L.-H. Han, and Z.-B. Wang, "Experimental behaviour of stiffened concrete-filled thin-walled hollow steel structural (HSS) stub columns," Journal of Constructional Steel Research, vol. 61, no. 7, pp. 962-983, 2005.

[11] J. Cai and Y.-L. Long, "Axial load behavior of rectangular cft stub columns with binding bars," Advances in Structural Engineering, vol. 10, no. 5, pp. 551-565, 2007.

[12] Y.-L. Long and J. Cai, "Stress-strain relationship of concrete confined by rectangular steel tubes with binding bars," Journal of Constructional Steel Research, vol. 88, pp. 1-14, 2013.

[13] Y.-T. Wang, J. Cai, and Y.-L. Long, "Hysteretic behavior of square cft columns with binding bars," Journal of Constructional Steel Research, vol. 131, pp. 162-175, 2017.

[14] Z.-L. Zuo, J. Cai, Q.-J. Chen, X.-P. Liu, C. Yang, and T.-W. Mo, "Performance of T-shaped CFST stub columns with binding bars under axial compression," Thin-Walled Structures, vol. 129, pp. 183-196, 2018.

[15] Z.-L. Zuo, J. Cai, C. Yang, and Q.-J. Chen, "Eccentric load behavior of L-shaped CFT stub columns with binding bars," Journal of Constructional Steel Research, vol. 72, pp. 105-118, 2012.

[16] Z.-L. Zuo, J. Cai, C. Yang, Q.-J. Chen, and G. Sun, “Axial load behavior of L-shaped CFT stub columns with binding bars," Engineering Structures, vol. 37, pp. 88-98, 2012.

[17] Z. L. Zuo, D. X. Liu, J. Cai, C. Yang, and Q. J. Chen, "Experiment on T-shaped CFT stub columns with binding bars subjected to axial compression," Advanced Materials Research, vol. 838-841, pp. 439-443, 2013.

[18] W. Zhao, J. Zhou, Z. Long, and W. Peng, "Compression performance of thin-walled square steel tube/bamboo plywood composite hollow columns with binding bars," Advances in Structural Engineering, vol. 21, no. 3, pp. 347-364, 2018.

[19] W. Zhang, Z. Chen, and Q. Xiong, "Performance of L-shaped columns comprising concrete-filled steel tubes under axial compression," Journal of Constructional Steel Research, vol. 145, pp. 573-590, 2018.

[20] J. Liu, Y. Yang, H. Song, and Y. Wang, "Numerical analysis on seismic behaviors of t-shaped concrete-filled steel tubular columns with reinforcement stiffeners," Advances in Structural Engineering, vol. 21, no. 9, pp. 1273-1287, 2018.

[21] Z.-B. Wang, Z. Tao, and Q. Yu, "Axial compressive behaviour of concrete-filled double-tube stub columns with stiffeners," Thin-Walled Structures, vol. 120, pp. 91-104, 2017.

[22] J. Y. R. Liew and D. X. Xiong, "Ultra-high strength concrete filled composite columns for multi-storey building construction," Advances in Structural Engineering, vol. 15, no. 9, pp. 1487-1503, 2012.

[23] F. Ding, X. Ding, X. Liu, H. Wang, Z. Yu, and C. Fang, "Mechanical behavior of elliptical concrete-filled steel tubular stub columns under axial loading," Steel and Composite Structures, vol. 25, no. 3, pp. 375-388, 2017.

[24] X. Liu, C. Xu, J. Liu, and Y. Yang, "Research on special-shaped concrete-filled steel tubular columns under axial compression," Journal of Constructional Steel Research, vol. 147, pp. 203-223, 2018.

[25] Z. Tao, B. Uy, L.-H. Han, and Z.-B. Wang, "Analysis and design of concrete-filled stiffened thin-walled steel tubular columns under axial compression," Thin-Walled Structures, vol. 47, no. 12, pp. 1544-1556, 2009.

[26] L.-H. Han, S.-H. He, L.-Q. Zheng, and Z. Tao, "Curved concrete filled steel tubular (CCFST) built-up members under axial compression: experiments," Journal of Constructional Steel Research, vol. 74, pp. 63-75, 2012.

[27] L.-H. Han, F. Chen, F.-Y. Liao, Z. Tao, and B. Uy, "Fire performance of concrete filled stainless steel tubular columns," Engineering Structures, vol. 56, pp. 165-181, 2013.

[28] Z. Tao, M. Ghannam, T.-Y. Song, and L.-H. Han, "Experimental and numerical investigation of concrete-filled stainless steel columns exposed to fire," Journal of Constructional Steel Research, vol. 118, pp. 120-134, 2016.

[29] V. I. Patel, B. Uy, K. A. Prajwal, and F. Aslani, "Confined concrete model of circular, elliptical and octagonal CFST short columns," Steel and Composite Structures, vol. 22, no. 3 , pp. 497-520, 2016.

[30] D. Pons, A. Espinos, V. Albero, and M. L. Romero, "Numerical study on axially loaded ultra-high strength concretefilled dual steel columns," Steel and Composite Structures, vol. 26, no. 6, pp. 705-717, 2018.

[31] C. Wang, Y. Shen, Y. Zou, T. Li, and X. Feng, "Stiffness degradation characteristics destructive testing and finiteelement analysis of prestressed concrete t-beam," Computer Modeling in Engineering \& Sciences, vol. 114, no. 1, pp. 75-93, 2018.

[32] J. Lubliner, J. Oliver, S. Oller, and E. Oñate, "A plastic-damage model for concrete," International Journal of Solids and Structures, vol. 25, no. 3, pp. 299-326, 1989. 


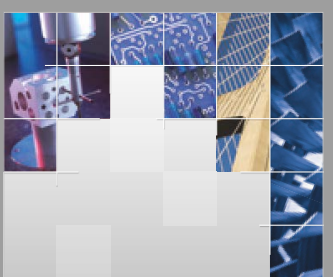

\section{Enfincering}
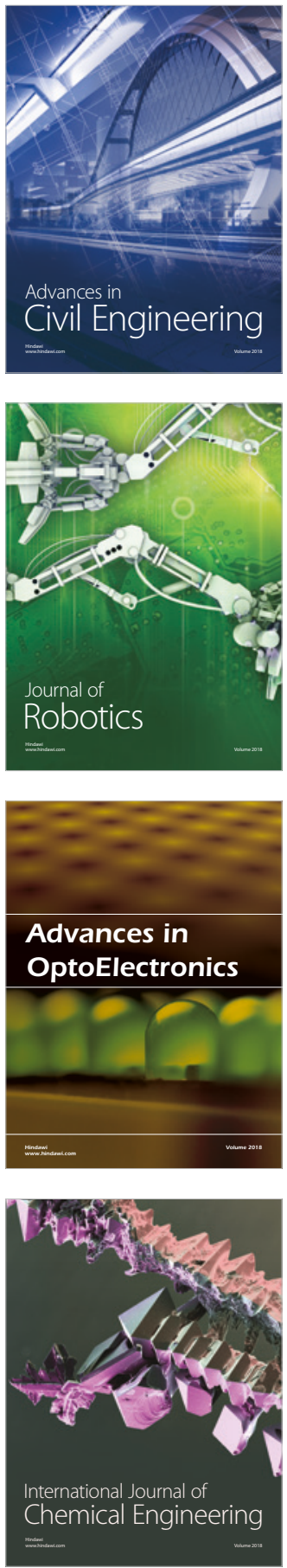

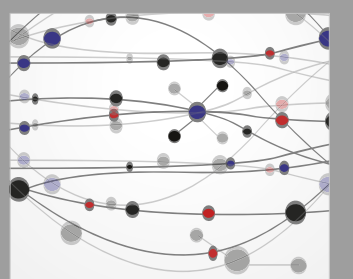

\section{Rotating \\ Machinery}

The Scientific World Journal

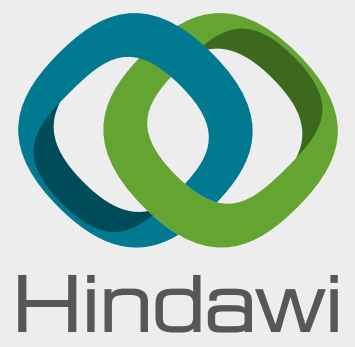

Submit your manuscripts at

www.hindawi.com
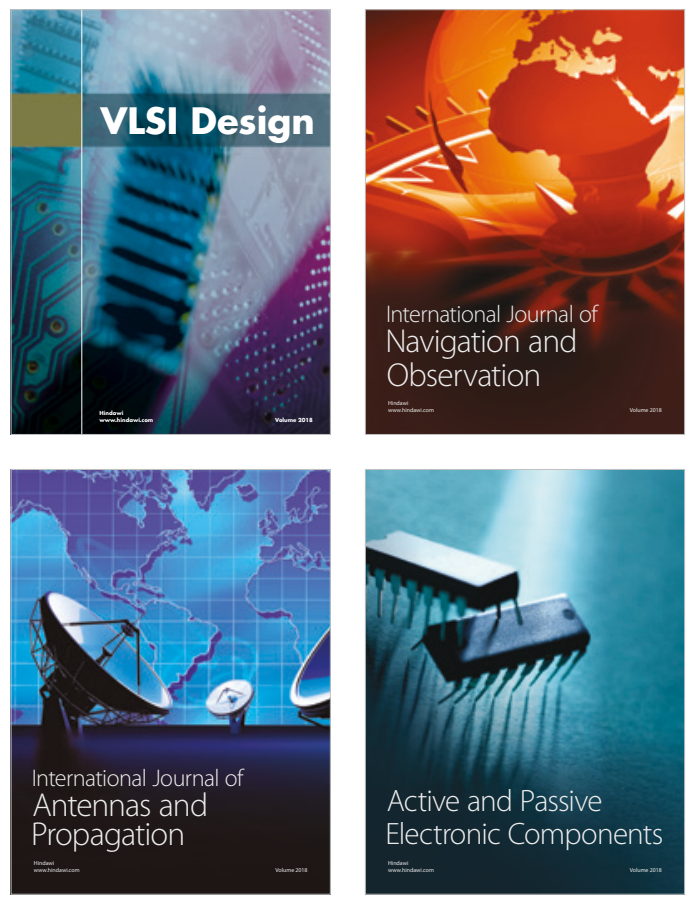
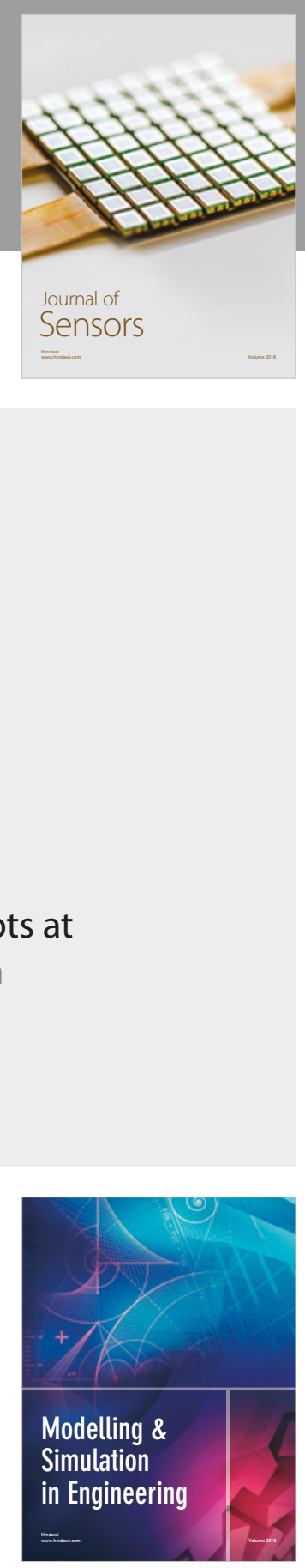

\section{Advances \\ Multimedia}
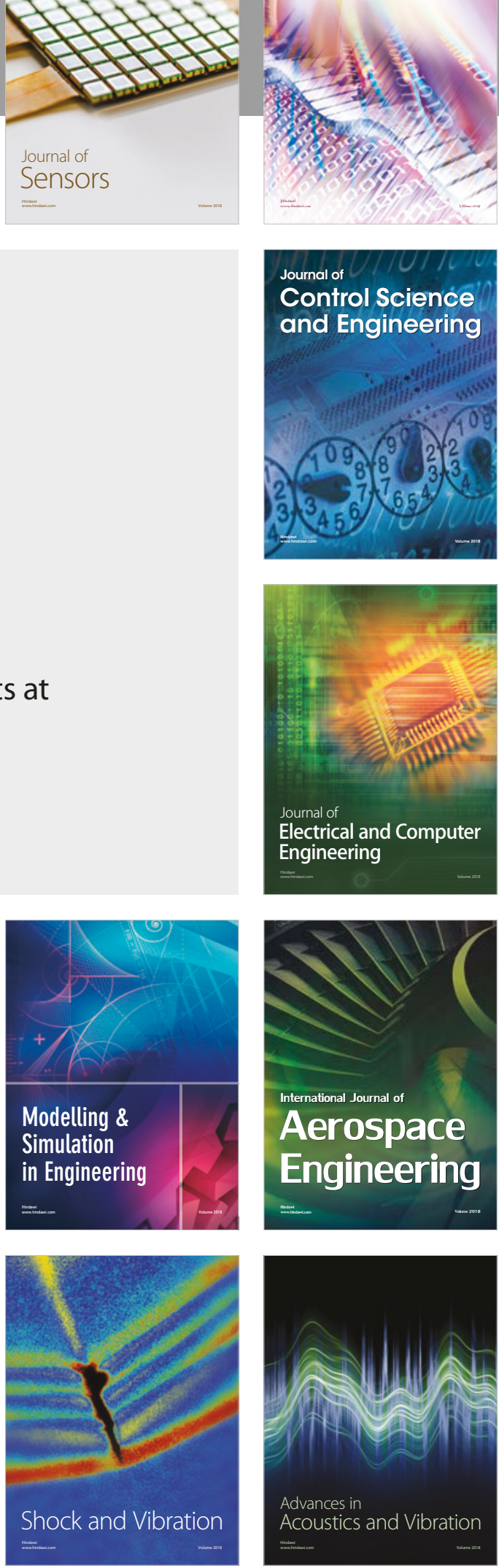